\title{
Extreme events in total ozone over Arosa - Part 2: Fingerprints of atmospheric dynamics and chemistry and effects on mean values and long-term changes
}

\author{
H. E. Rieder ${ }^{1}$, J. Staehelin ${ }^{1}$, J. A. Maeder ${ }^{1}$, T. Peter ${ }^{1}$, M. Ribatet ${ }^{2}$, A. C. Davison ${ }^{2}$, R. Stübi ${ }^{3}$, P. Weihs ${ }^{4}$, and F. Holawe ${ }^{5}$ \\ ${ }^{1}$ Institute for Atmospheric and Climate Science, ETH Zurich, Zurich, Switzerland \\ ${ }^{2}$ Institute of Mathematics, EPF Lausanne, Lausanne, Switzerland \\ ${ }^{3}$ Federal Institute of Meteorology and Climatology (MeteoSwiss), Payerne, Switzerland \\ ${ }^{4}$ Institute for Meteorology, University of Natural Resources and Applied Life Sciences (BOKU), Vienna, Austria \\ ${ }^{5}$ Institute for Geography and Regional Research, University of Vienna, Vienna, Austria
}

Received: 22 April 2010 - Published in Atmos. Chem. Phys. Discuss.: 18 May 2010

Revised: 31 August 2010 - Accepted: 22 September 2010 - Published: 25 October 2010

\begin{abstract}
In this study the frequency of days with extreme low (termed ELOs) and extreme high (termed EHOs) total ozone values and their influence on mean values and trends are analyzed for the world's longest total ozone record (Arosa, Switzerland). The results show (i) an increase in ELOs and (ii) a decrease in EHOs during the last decades and (iii) that the overall trend during the 1970s and 1980s in total ozone is strongly dominated by changes in these extreme events. After removing the extremes, the time series shows a strongly reduced trend (reduction by a factor of 2.5 for trend in annual mean). Excursions in the frequency of extreme events reveal "fingerprints" of dynamical factors such as ENSO or NAO, and chemical factors, such as cold Arctic vortex ozone losses, as well as major volcanic eruptions of the 20th century (Gunung Agung, El Chichón, Mt. Pinatubo). Furthermore, atmospheric loading of ozone depleting substances leads to a continuous modification of column ozone in the Northern Hemisphere also with respect to extreme values (partly again in connection with polar vortex contributions). Application of extreme value theory allows the identification of many more such "fingerprints" than conventional time series analysis of annual and seasonal mean values. The analysis shows in particular the strong influence of dynamics, revealing that even moderate ENSO and NAO events have a discernible effect on total ozone. Overall the approach to extremal modelling provides new information on time series
\end{abstract}

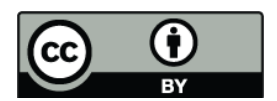

Correspondence to: $\mathrm{H}$. E. Rieder (harald.rieder@env.ethz.ch) properties, variability, trends and the influence of dynamics and chemistry, complementing earlier analyses focusing only on monthly (or annual) mean values.

\section{Introduction}

Downward trends in global stratospheric ozone during recent decades have been shown to be directly linked to increasing surface UV-radiation (e.g. Calbo et al., 2005). The successful implementation of the Montreal Protocol (e.g. WMO, 2007) started the discussion on ozone recovery (e.g. Austin and Wilson, 2006; Eyring et al., 2007; Harris et al., 2008; Shepherd, 2008; Hegglin and Shepherd, 2009; Waugh et al., 2009). In the past, long-term ozone trends were determined from homogenized data series by fitting with multiple linear regression models, in which suitable independent variables (so-called explanatory variables) were used to represent atmospheric variability, such as the Quasi-Biennial Oscillation (QBO), the 11-year solar cycle, and a linear trend attributed to anthropogenic ozone depletion (e.g. Staehelin et al., 2001; WMO, 2003). Previous studies have identified a number of other processes influencing total ozone at mid-latitudes, such as synoptic-scale meteorological variability (e.g. Dobson and Harrison, 1926; Steinbrecht et al., 1998; Shepherd, 2008), decadal or long-term climate variability (e.g. Hood and Zaff, 1995; Chandra et al., 1996; Hood, 1997), described e.g. by the Northern Atlantic Oscillation (NAO) (e.g. Appenzeller et al., 2000; Orsolini and Doblas-Reyes, 2003), the Arctic

Published by Copernicus Publications on behalf of the European Geosciences Union. 
Oscillation (AO) (e.g. Thompson and Wallace, 2000), atmospheric circulation indices (e.g. Brönnimann and Hood, 2003), ENSO (e.g. Brönnimann et al., 2004a), temperature at the 470-K isentrope level (e.g. Mäder et al., 2007), and volcanic eruptions (e.g. Pittock, 1965; Grams and Fiocco, 1967; Jaeger and Wege, 1990; Yue et al., 1991; McCormick et al., 1995; Solomon, 1999; Robock, 2000; Mäder et al., 2007). There is broad agreement that long-term ozone trends at mid-latitudes are dominated by ozone depleting substances (ODS), whereas ozone changes during short periods may be attributable to changes in horizontal advection and convergence or divergence of mass related to changes in tropospheric and lower stratospheric pressure systems (e.g. Koch et al., 2005; Wohltmann et al., 2007; Mäder et al., 2007).

Several studies (e.g. WMO, 2007; Harris et al., 2008) showed that the major cause of decline of total ozone at northern mid-latitudes from 1970 to the mid-1990s was the increase of stratospheric concentrations of ODS. From 1992 to 1994 the Mt. Pinatubo eruption of 1991 had a significant influence on ozone in the northern mid-latitudes. This effect has been larger than that of El Chichón in 1982 (e.g. Harris et al., 2008). Although equivalent effective stratospheric chlorine (EESC) had the largest influence on total ozone changes over the northern mid-latitudes (e.g. Mäder et al., 2007; Harris et al., 2008) dynamical changes had a strong influence too. Dynamical changes have been more important over Europe than in other regions of the world (e.g. Appenzeller et al., 2000; Staehelin et al., 2001; WMO, 2003). According to Wohltmann et al. (2007) and Maeder et al. (2007), dynamic processes could account for about $30 \%$ of the ozone decline starting in the 1970s. Koch et al. (2005) found that the increase in fast isentropic transport of tropical air to midlatitudes contributed to ozone changes over Europe between 1980 and 1989. Other studies performed within the EU project CANDIDOZ (Harris et al., 2008) and summarized in the WMO/UNEP Ozone Assessment (WMO, 2007) indicate that the increase in total ozone after the mid-1990s is mainly caused by dynamic changes, while the change in ODS only contributed insignificantly to the observed ozone increase at northern mid-latitudes (e.g. Hood and Soukharev, 2005; Harris et al., 2008; Shepherd, 2008; Hegglin and Shepherd, 2009).

This study deals with the frequency distribution of extreme events in low and high total ozone (ELOs, EHOs), their influence on mean values and trends, and "fingerprints" of major atmospheric processes in total ozone. This paper is complementary to its companion paper, which deals with the basic concept of applying extreme value theory to stratospheric ozone (Rieder et al., 2010, hereafter called Part 1).

\section{Data and methods}

\subsection{Data}

In this study we analyze the world's longest total ozone record from Arosa, Switzerland, which is based on direct sun measurements with Dobson spectrophotometers and has been homogenized (for details see Staehelin et al., 1998a, b). Data on total ozone from Arosa is provided by the World Ozone and Ultraviolet Radiation Data Centre (WOUDC, http://www.woudc.org).

Several indices describing atmospheric dynamics (e.g. El Niño Southern Oscillation (ENSO), North Atlantic Oscillation (NAO)) and chemistry (volcanic eruptions, ODS in general and polar vortex ozone loss in particular) have been used in this study. Table 1 contains an overview of the datasets used (including their sources).

\subsection{Methods}

The Generalized Pareto Distribution (GPD) is commonly used in the analysis of rare events. It arises as the natural distribution of the excess of a variable above (below) a sufficiently high (low) threshold (e.g. Davison and Smith, 1990). The use of the GPD for modelling extremes is justified by asymptotic arguments (e.g. Pickands, 1975; Coles, 2001), as the GPD is the limiting distribution of normalized excesses beyond a threshold, as the threshold approaches the endpoint of the distribution.

The GPD (see Eq. 1) of a variable $x$ is defined by 3 parameters: the threshold value $u$, the scale parameter $\sigma$ and the shape parameter $\xi$ :

$F(x)=1-\left[1+\xi \frac{x-u}{\sigma}\right]^{-1 / \xi} ;$
$\sigma>0, x>u, 1+\xi \frac{x-u}{\sigma}>0$.

Here, $u$ defines which values of the variable $x$ can be considered as extremes, while $\sigma$ takes account of the scale of the variable $x$ (i.e., is determined by its units), and $\xi$ determines the shape of the tail of the distribution. In the present application the task is to fit the GPD to the tails of daily total ozone data from Arosa (i.e., to very low and high values) on monthly basis. In an accompanying paper (Part 1) the application of extreme value theory, including threshold selection (based on mean residual life plots and threshold choice plots) and threshold evaluation (based on QuantileQuantile comparisons of observed and modeled extremes and density plots) is described in more detail. Threshold values have been determined on a monthly basis for the periods 1927-1959 (considered as pre-industrial with respect to anthropogenic emission of ODS and volcanic disturbance) and 1960-2008 (considered as industrial with respect to anthropogenic emission of ODS and volcanic disturbance). To avoid monthly leaps, threshold values have been extrapolated 
Table 1. Overview of datasets used in this study. NOTE: datasets marked with (+) have not been available for the entire time period (1927-2008) analysed.

\begin{tabular}{|c|c|c|}
\hline Data & $\begin{array}{l}\text { Time range } \\
\text { (resolution) }\end{array}$ & Source \\
\hline Total ozone (Arosa) & $\begin{array}{l}\text { 1927-2008 } \\
\text { (daily) }\end{array}$ & $\begin{array}{l}\text { World Ozone and Ultraviolet Radiation Data } \\
\text { Centre (WOUDC) http://www.woudc.org }\end{array}$ \\
\hline NINO3.4 Index & $\begin{array}{l}\text { 1927-2007 } \\
\text { (monthly) }\end{array}$ & $\begin{array}{l}\text { NCAR/UCAR Climate and Global dynamics } \\
\text { http://www.cgd.ucar.edu/cas/catalog/climind/ } \\
\text { TNI_N34/index.html }\end{array}$ \\
\hline NAO Index & $\begin{array}{l}\text { 1927-2008 } \\
\text { (seasonal) }\end{array}$ & $\begin{array}{l}\text { NCAR/UCAR Climate and Global dynamics } \\
\text { http://www.cgd.ucar.edu/cas/jhurrell/indices. } \\
\text { data.html\#naostatmon }\end{array}$ \\
\hline SATO Index $^{+}$ & $\begin{array}{l}1927-2000 \\
\text { (monthly) }\end{array}$ & $\begin{array}{l}\text { NASA Goddard Institute for Space studies } \\
\text { http://data.giss.nasa.gov/modelforce/strataer/ }\end{array}$ \\
\hline ODS (in EESC) ${ }^{+}$ & $\begin{array}{l}\text { 1950-2008 } \\
\text { (monthly) }\end{array}$ & $\begin{array}{l}\text { NASA Goddard Institute for Space studies } \\
\text { http://acdb-ext.gsfc.nasa.gov/Data_services/ } \\
\text { automailer/ }\end{array}$ \\
\hline $\begin{array}{l}\text { Polar vortex ozone loss } \\
\text { contributions to northern } \\
\text { mid-latitudes column ozone }\end{array}$ & $\begin{array}{l}1970-2004 \\
\text { (winter } \\
\text { averages) }\end{array}$ & $\begin{array}{l}\text { Wohltmann et al. (2007) (I. Wohltmann, } \\
\text { personal communication, 2009) }\end{array}$ \\
\hline
\end{tabular}

to daily values by linear interpolation (see Part 1). Sensitivity analysis showed that the time periods for threshold selection do not significantly affect the frequency of ELOs and EHOs and that the main findings of the study are robust and do not depend on the time windows used for threshold determination (see Part 1 and its supplementary material).

\section{Results and discussion}

\subsection{Frequency of extreme events in total ozone on annual and seasonal scale}

The classification of total ozone observations on days with extreme low (ELOs), extreme high (EHOs) and non-extreme days (NEOs) was described in an accompanying paper (see Part 1). The following discussion of the frequency of extreme events in total ozone on annual and seasonal basis, considering threshold values for anthropogenically and volcanically unperturbed (1927-1959) and perturbed (1960-2008) periods, is based on this classification. The observed frequency for all three groups is plotted as a time series in Fig. 1c.

The earliest part of the total ozone time series of Arosa (before 1932) suffers from a calibration uncertainty and large gaps in the measurements (see Staehelin et al., 1998a, b). It appears that the first 20 years of the Arosa record reveal natural variability in ELOs and EHOs (on average $~ 10 \%$ ). In 1940-1942 a strong enhancement in EHOs is visible (due to a strong ENSO event) (Brönnimann et al., 2004a, b), followed by a second period of approximately 30 years of moderate natural variability. Overall the number of EHOs is slightly larger than the number of ELOs during the first 40 years of the Arosa record. EHOs are indicative for northerly advection of $\mathrm{O}_{3}$-rich airmasses from the high-latitude lowermost stratosphere, while ELOs are indicative for southerly winds of $\mathrm{O}_{3}$-poor airmasses from the direction of the subtropical jet (e.g. Koch et al., 2005). Therefore, the predominance of EHOs over Arosa, which is situated north of the Alpine main ridge, may be interpreted as a predominant influence of northerly intrusions. From the late 1970s a decrease in the number of EHOs and an increase in the frequency of ELOs are observed. This is in general agreement with the notion that the tropical band widened and the polar regime shrank over the past decades (Hudson et al., 2006; Seidel et al., 2008). During the last 5-10 years a decrease in the frequency of ELOs and a stabilization or small increase in the frequency of EHOs can be observed over Arosa, in general agreement with the notion that anthropogenic ozone depletion has come to a halt.

Figure $2 \mathrm{a}-\mathrm{d}$ shows the observed frequency of ELOs and EHOs for the different seasons of the year (spring = MAM, summer $=J J A$, autumn $=S O N$, winter $=\mathrm{DJF})$. On seasonal scale we see a strong increase in ELOs from the 1970s on and a corresponding decrease in EHOs, especially in winter and spring. The highest frequency of days with extreme low 


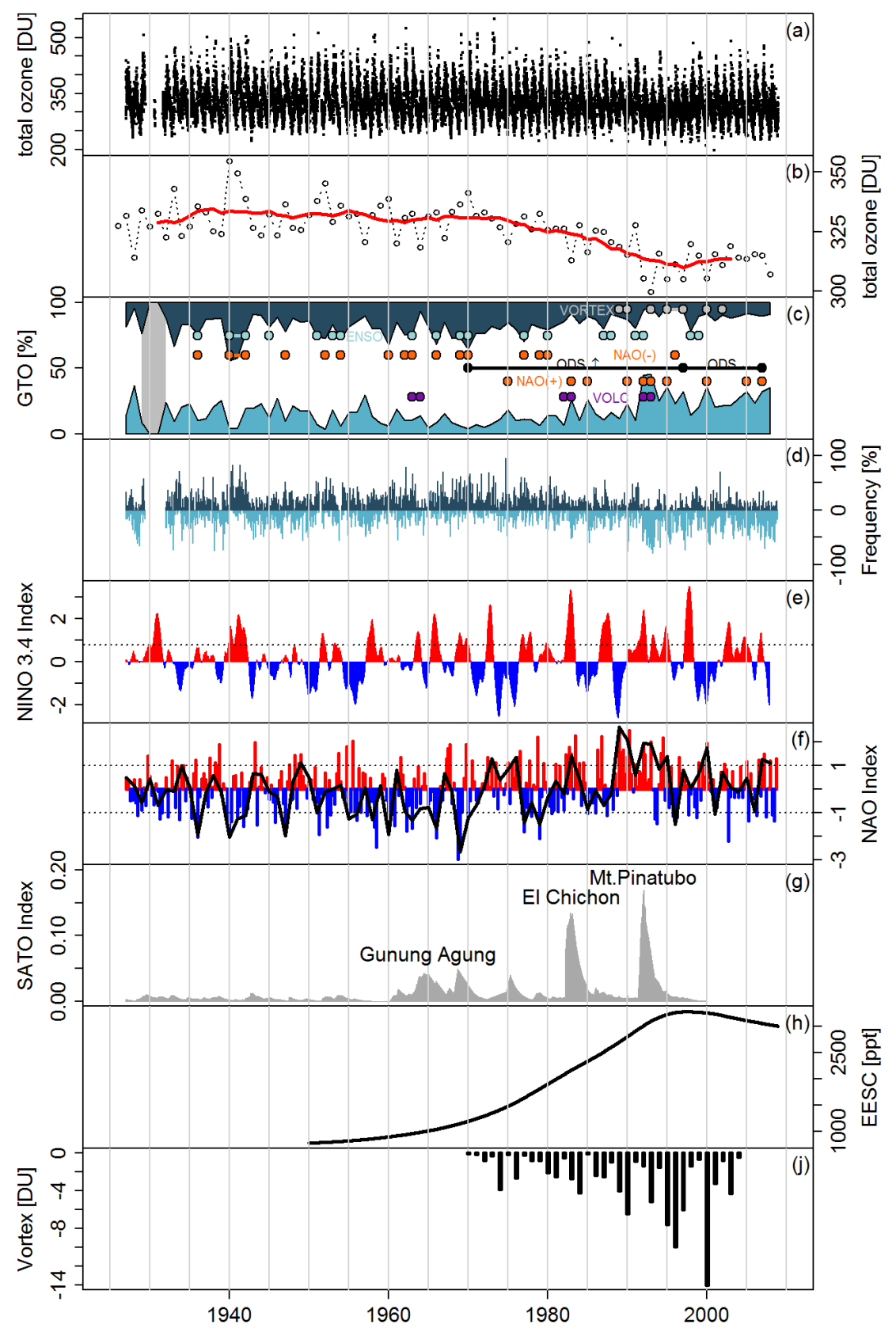

Fig. 1. (a) Daily observations of total ozone at Arosa, Switzerland, (b) yearly averages and 11-year running mean (red line) of total ozone at Arosa, (c) yearly evolution of fractions of extreme events (GTO) in low (ELOs - light blue area) and high (EHOs - dark blue area) total ozone and not extreme days (NEOs - white area). Global modes refer to "fingerprints" of ENSO (light blue), NAO (orange), strong polar vortex ozone loss (grey), volcanic eruptions of Gunung Agung, El Chichón and Mt. Pinatubo (purple) and the development of ODS (black lines). Grey vertical bar for 1929-1931 indicates periods of missing data. (d) Frequency of EHOs (dark blue) and ELOs (light blue) on monthly time scale. Indices for (e) El Niño Southern Oscillation (ENSO), monthly NINO3.4 Index, vertical dotted line marks 0.7 values, (f) North Atlantic Oscillation, seasonal NAO Index (principal components of the leading empirically-determined orthogonal function of seasonal sea level pressure anomalies over the Atlantic sector $\left(20^{\circ} \mathrm{N}-80^{\circ} \mathrm{N}, 90^{\circ} \mathrm{W}-40^{\circ} \mathrm{E}\right)$ from Hurrel, 2009), black line shows NAO Index for DJFM, vertical dotted lines marks \pm 1 values and (g) volcanic aerosol loading in terms of mean optical thickness, monthly Sato Index for the Northern Hemisphere (Sato et al., 1993) (major volcanic eruptions of Gunung Agung (1963), El Chichón (1982) and Mt. Pinatubo (1991) are marked). (h) Atmospheric loading of ODS in terms of equivalent effective stratospheric chlorine (EESC) on monthly basis. (j) Estimates of the contribution of ozone destruction in the polar vortex to column ozone at the northern mid-latitudes in late winter and spring (in DU) (data from IWohltmann et al. (2007), I. Wohltmann, personal communication, 2009). For data sets of indices used see Table 1. 


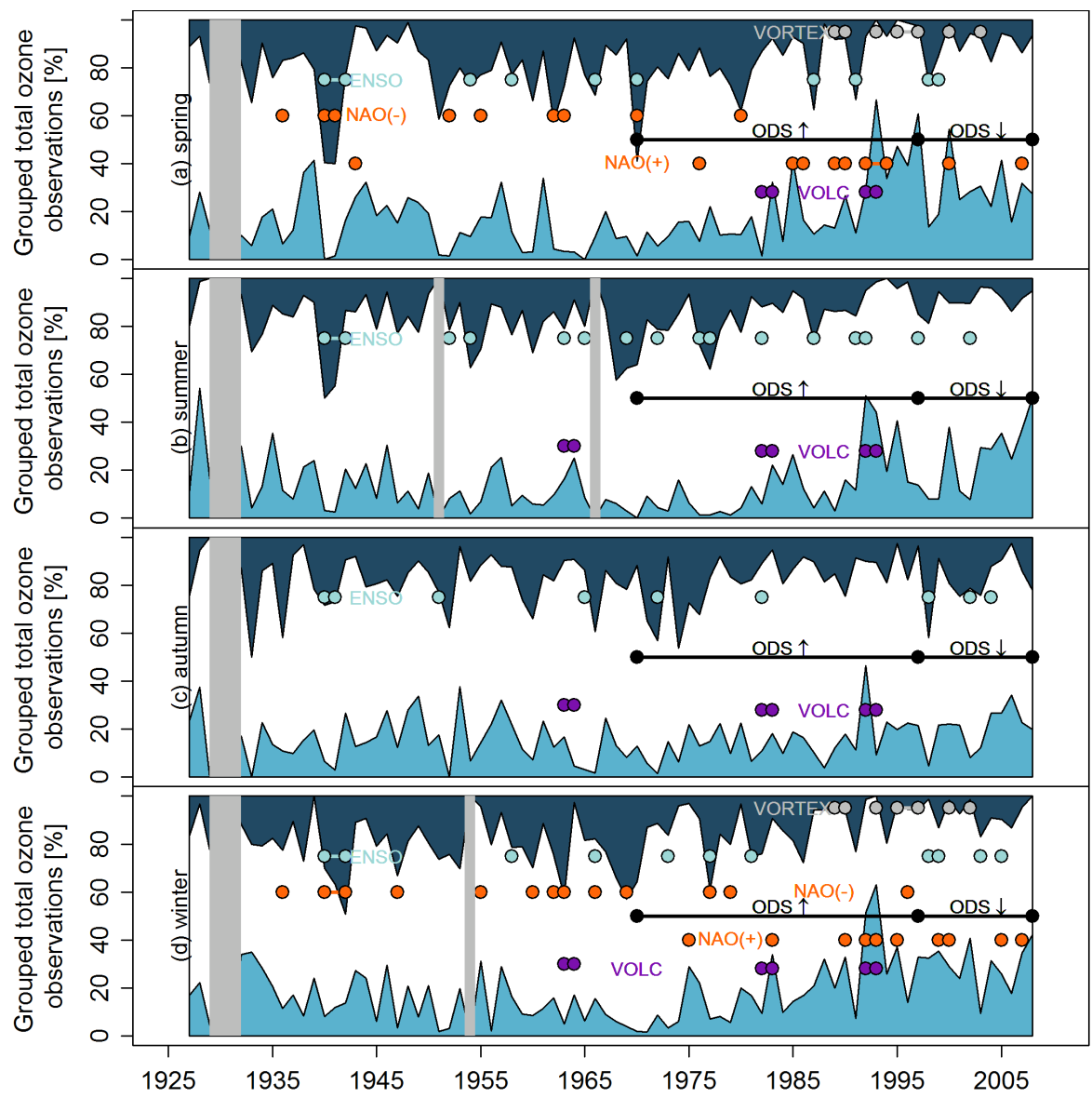

Fig. 2. Evolution of fractions of extreme events (GTO) in low (ELOs-light blue area) and high (EHOs-dark blue area) total ozone and nonextreme days (NEOs-white area) for (a) spring, (b) summer, (c) autumn and (d) winter in 1927-2008. See Fig. 1c for corresponding annual mean. Colored circles show global modes distinguished by the following indices: ENSO (light blue), NAO (orange), volcanic eruptions of Gunung Agung, El Chichón and Mt. Pinatubo (purple), polar vortex ozone loss (grey) and increasing/decreasing long-term development of ODS (black). Grey vertical bars denote periods of missing data.

total ozone and smallest frequency of days with extreme high total ozone is found in the years following the eruption of Mt. Pinatubo and in years with strong contributions of ozonepoor air after breakdown of the polar vortex. The highest frequency of EHOs and lowest frequency of ELOs is found during phases with strong El Niño Southern Oscillation.

Dynamical effects (e.g. related to ENSO or NAO) and chemical effects (e.g. contributions of strong polar vortex ozone loss) as well as combined dynamical/chemical effects (e.g. major volcanic eruptions) on column ozone over the northern mid-latitudes have been discussed in various studies (e.g. ENSO in 1940-1942 (Brönnimann et al., 2004a, b); NAO (e.g. Appenzeller et al., 2000; Orsolini and Limpasuvan, 2001); mixing of airmasses after the breakdown of the polar vortex (e.g. Knudsen and Grooss, 2000; Fioletov and Shepherd, 2005); volcanic effects (e.g. Brasseur and Granier, 1992)). However "fingerprints" of these events have so far been identified only in particular cases, but not coherently, irrespective of the magnitude of the events. The current study enables such identification by applying extreme value theory (compare Fig. 3). Solar cycle and QBO effects (regularly included as explanatory variables in statistical regression analysis on total ozone, e.g. Mäder et al., 2007; Vyushin et al., 2007; Wohltmann et al., 2007; WMO, 2007) however, are not included in our study as they show continuous, but small (1-2\%), influence on total ozone.

Below we show how extreme value modeling helps to attribute ozone variability to the dynamical and/or chemical mechanisms. Expected and observed dynamical and chemical effects on total ozone are discussed in detail in the scientific literature (see Sect. 3.2). From this knowledge we deduce (by visual inspection) whether "fingerprints" of such events are visible in the frequency of extremes (ELOs and/or EHOs on annual/seasonal basis). "Fingerprints" of these mechanisms are discernible in the extreme part of the Arosa time series even when no attribution is possible from mean value analysis (see Fig. 3). Below we discuss these different factors in more detail. 

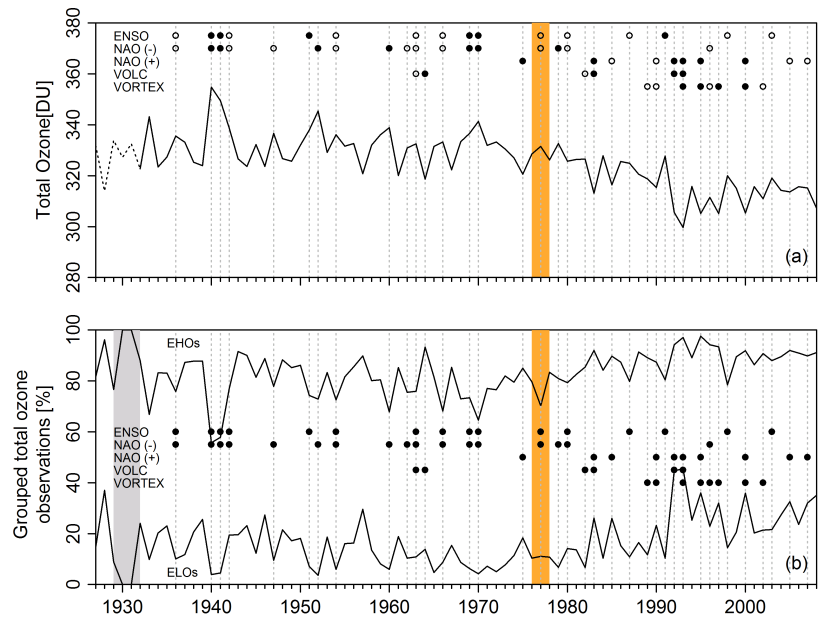

Fig. 3. Comparison of visibility of "fingerprints" of atmospheric dynamics and chemistry between (a) annual mean values and (b) frequency distribution of EHOs and ELOs (annual basis). Global modes are marked in each line. Filled circles denote visible "fingerprints" and open circles denote not visible "fingerprints". To illustrate differences between (a) and (b) the year 1977 is selected (highlighted by orange bar), when an increase in column ozone is expected because of a strong negative NAO and a strong positive ENSO event (see Sect. 3.2). While clear "fingerprints" are visible in the frequency distribution of EHOs (see b) no signal (no real difference to mean values in neighbouring years) is visible for the annual mean value (see a).

\subsection{Atmospheric dynamics and chemistry}

Figure 1 provides an overview of the temporal evolution of the various indices used to describe atmospheric dynamics and chemistry.

\subsubsection{EI Niño/Southern Oscillation (ENSO)}

The El Niño/Southern Oscillation (ENSO) phenomenon is one of the most prominent modes of climate variability (Diaz and Markgraf, 2000), well known to affect climate and weather in large parts of the world. Strong ENSO events (e.g. 1940-1942) are triggered by the high contrast between high tropical and low extra-tropical Pacific sea surface temperatures (Brönnimann et al., 2004a; Brönnimann et al., 2004b), as these events are known to affect the North Pacific and surrounding areas via changes in the Hadley circulation and Rossby wave generation (e.g. Trenberth et al., 1998; Alexander et al., 2002). However, the precise extent of the influence of ENSO on European winter climate and the northern stratosphere remains a matter of debate (e.g. Friedrich and Müller, 1992; Pozo-Vazquez et al., 2001; Greatbatch et al., 2004). Other studies have shown that the ENSO winter signal over Europe consists of cold temperatures in Northern Europe, high sea level pressure from Iceland to Scandinavia, and low sea level pressure over central and western Europe (e.g. Friedrich and Müller, 1992; Merkel and Latif,
2002; Greatbatch et al., 2004). Several studies have shown that strong ENSO events are associated with a weak(er) polar vortex and more frequent stratospheric warming (van Loon and Labitzke, 1987; Labitzke and van Loon, 1999), as a stronger wave activity flux diminishes the vortex strength and strengthens the meridional circulation in the middle stratosphere, leading to enhanced transport of ozone from the tropics to the extra tropics, stronger descent over the polar region, a warmer lower stratosphere and enhanced total ozone in the Arctic in late winter (e.g. Newman et al., 2001; Randel et al., 2002). Influence of strong ENSO events on surface temperatures and column ozone over the northern mid-latitudes was shown by Brönnimann et al. (2004b).

The evolution of the ENSO index (Nino 3.4 Index) is shown in Fig. 1e. In the frequency distribution of EHOs (Fig. 1c, d and Fig. 2a-d), the "fingerprints" of several El Niño events (ENSO index larger than 0.7) are visible, but their amplitude differs among the seasons. On the seasonal scale ENSO "fingerprints" are found for spring (Fig. 2a) in 1940-1942, 1954, 1958, 1966, 1970, 1987, 1991 and 19981999 and winter (Fig. 2d) in 1940-1942, 1958, 1966, 1973, 1977, 1981, 1991 and 1998-1999, 2003 and 2005. In summer and autumn ENSO "fingerprints" are less pronounced but still discernible. "Fingerprints" are visible during summer (Fig. 2b) in 1940-1942, 1952, 1954, 1963, 1965-1966, 1969, 1972, 1976-1977, 1982, 1987, 1991-1992 1997 and 2002 and during autumn (Fig. 2c) in 1940-1941, 1951, 1965, 1969, 1972, 1982, 1998, 2002 and 2004. In contrast to previous studies that reported only on the influence of the strongest El Niño events (Brönnimann et al., 2004a, b; Sassi et al., 2004), the present analysis reveals that also moderate El Niño events (ENSO Index larger than 0.7) have a significant influence on column ozone over Europe.

\subsubsection{North Atlantic Oscillation (NAO)}

Interannual and decadal changes in tropospheric meteorology and lower stratospheric dynamics may be related to the strengthening of the Arctic Polar Vortex, the weakening of the Brewer-Dobson circulation, changes in the Arctic Oscillation (AO) and North Atlantic Oscillation (NAO), and to reductions in tropopause height and temperatures in the lower stratosphere (e.g. Pawson and Naujokat, 1999; Hurrell, 1995; Thompson and Wallace, 1998; Steinbrecht et al., 1998; Randel and Wu, 1999; Newman and Nash, 2000; Wallace, 2000). Total ozone in the Northern Hemisphere is influenced by modes in the variability of the atmospheric circulation, such as the Arctic Oscillation (AO) or the North Atlantic Oscillation (NAO), both affecting winter climate in Europe and the strength of the winter Arctic vortex (Appenzeller et al., 2000; Thompson and Wallace, 2000; Orsolini and Limpasuvan, 2001; Hadjinicolaou et al., 2002; Orsolini and Doblas-Reyes, 2003). Conversely, changes in ozone can also feed back to the global circulation (Volodin and Galin, 1998; Hartmann et al., 2000), although evidence that this is a major factor in the 
northern mid-latitudes is lacking (Braesicke and Pyle, 2003). The NAO is the leading mode of the interannual variability in the Euro-Atlantic sector and shows strong effects on the northern hemispheric troposphere, as it influences many meteorological parameters (e.g. temperature, precipitation). The NAO influences changes in the direction and intensity of the dominant westerly tropospheric jet stream over the Atlantic (e.g. Orsolini and Limpasuvan, 2001) and is the main driver of the inter-annual variability in storm tracks over the Atlantic during the cold season (e.g. Lau, 1988). Tropopause pressure is higher during positive NAO phases at high latitudes and lower mid-latitudes, as expected from an enhanced Icelandic low and Azores high pressure system (e.g. Appenzeller et al., 2000). During its positive phase the NAO is associated with an enhancement of ozone over Labrador/southern Greenland and a lowering of ozone over Europe (Orsolini and Doblas-Reyes, 2003), while during its negative phase (weak Icelandic low and strong Azores high) it is associated with enhancement of ozone over Europe (e.g. Brönnimann et al., 2004a; Brönnimann et al., 2004b). The NAO index (and the related AO) has changed since the 1960s (e.g. Hurrell, 1995; Thompson and Wallace, 2000; Appenzeller et al., 2000), while the Arctic polar vortex strengthened. A stronger northern polar vortex (similar to its Antarctic counterpart) is concomitant with a slower Brewer-Dobson circulation and, consequently, with lower column ozone in high latitudes (Chipperfield and Jones, 1999; Hadjinicolaou et al., 2002).

Figure 1f shows the evolution of the NAO index (principal components of the leading empirically-determined orthogonal function of seasonal sea level pressure anomalies over the Atlantic sector $\left(20^{\circ} \mathrm{N}-80^{\circ} \mathrm{N}, 90^{\circ} \mathrm{W}-40^{\circ} \mathrm{E}\right)$ from Hurrel, 2009). Several NAO fingerprints are visible during spring and winter in the extremes record (see Fig. 1 and Fig. 2a, d). We see "fingerprints" of NAO in its negative phase (NAO Index smaller -1), leading to higher column ozone over Europe, in 1936, 1940-1942, 1952, 1955, 1960, 1963, 1966, 1969-1970, 1977 1979-1980 and 1996 as well as during its positive phase (NAO Index larger than 1), leading to lower column ozone over Europe in 1975, 1981, 1983, 1985, 1989 1990, 1992-1993, 1995, 2000, 2005, 2007 and 2008. However, the influences of ENSO and contributions from strong polar ozone depletion and NAO often occur in the same years, which renders discrimination of their effects difficult. We fitted generalized linear models with quasi-Poisson error structure (e.g. McCullagh and Nelder, 1989; Hastie and Pregibon, 1992) to assess the relation between the NAO Index and the numbers of days with extreme high and low total ozone. These models show that higher NAO significantly (at $5 \%$ ) increases the numbers of ELOs and decreases the numbers of days with EHOs in winter and spring, and also on an annual basis (see Table 2).

\subsubsection{Volcanic eruptions}

Gaseous compounds including $\mathrm{SO}_{2}$ and $\mathrm{H}_{2} \mathrm{~S}$ enter the stratosphere through volcanic eruptions (e.g. Staehelin et al., 2001). While $\mathrm{H}_{2} \mathrm{~S}$ is very rapidly converted to $\mathrm{SO}_{2}$, this gas is subsequently oxidized to $\mathrm{H}_{2} \mathrm{SO}_{4}$, which undergoes bimolecular nucleation with water to form new aqueous $\mathrm{H}_{2} \mathrm{SO}_{4}$ droplets or condenses on pre-existing $\mathrm{H}_{2} \mathrm{SO}_{4}-\mathrm{H}_{2} \mathrm{O}$ droplets. Large enhancements of aqueous sulfuric acid aerosols by volcanic eruptions strongly affect the ozone layer via two mechanisms: first, they impact the chemistry of the lower stratosphere, mainly by providing surfaces for heterogeneous processes resulting in ozone depletion; second, they alter stratospheric dynamics due to their infrared absorptivity leading to lower stratospheric heating (Brasseur and Granier, 1992; Kodera, 1994; Hadjinicolaou et al., 1997). The temporal evolution of the Sato Index (Sato et al., 1993), which describes volcanic aerosol in terms of its mean optical thickness is shown in Fig. 1g.

Throughout all seasons "fingerprints" of the volcanic eruptions of El Chichón (March/April 1982) and Mount Pinatubo (June 1991) are visible in the extremes of the time series, through a strong increase in ELOs and almost complete erosion in EHOs, see Figs. 1c, 2 and 3b. After the eruption of El Chichón strong influence of ELOs on observed ozone mean values is visible mainly during winter 1982/1983 and spring 1983 (see Fig. 2a and d). Even larger influence on the frequency of extreme events and their influence on observed mean values ( $>20 \mathrm{DU}$ ) is obvious after the eruption of Mount Pinatubo in 1992 (all seasons) and winter and spring of 1993. For the third largest volcanic eruption, Gunung Agung in May 1963, the extremes record shows less clear "fingerprints". However, a strong ENSO event that occurred in the same year may disguise the influence of the volcanic eruption on column ozone.

\subsubsection{Strong polar vortex ozone loss and ozone depleting substances}

In the early 1950s the industrial chemical production of ozone-depleting substances (ODS) began. Shortly after the publications of Molina and Rowland (1974) and Rowland and Molina (1975), the deployment of CFC-11 and CFC-12 as spray propellants was prohibited in some countries, leading to a reduction in their worldwide production. However, emissions of these compounds increased again from 1982 up to 1987. The negative impact on column ozone of anthropogenically produced CFCs has been widely studied (e.g. Molina and Rowland, 1974; Cicerone et al., 1974; Rowland and Molina, 1975; WMO, 2003, 2007). In 1987 the representatives of national governments reached an agreement, the Montreal Protocol, to reduce the global emission of substances leading to stratospheric ozone destruction (e.g. Staehelin et al., 2001). It led to a decrease in global production and therefore also in release of CFCs and other ODS. 
Table 2. Parameter estimates of the generalized linear model for the connection between North Atlantic Oscillation (NAO) Index and the number of days with extreme high (EHOs) and low (ELOs) total ozone in spring, winter and on an annual basis. All values are significant at at least the $95 \%$ level. Standard errors are given in brackets.

\begin{tabular}{lrr}
\hline & EHOs & ELOs \\
\hline Winter & $-0.34(0.06)$ & $0.37(0.06)$ \\
Spring & $-0.30(0.07)$ & $0.19(0.07)$ \\
Annual & $-0.39(0.07)$ & $0.32(0.11)$ \\
\hline
\end{tabular}

Depending on their physical and chemical properties, the various halogen compounds have different potentials to deplete ozone. Mostly they are described in terms of EESC (equivalent effective stratospheric chlorine) which is the sum of chlorine containing species multiplied by the number of $\mathrm{Cl}$ atoms contained in the compound and weighted by their fractional stratospheric release rate. EESC also accounts for the effects of bromine species (e.g. WMO, 2003). EESC increased from the 1950s on, peaking in 1997 and then started to decline slowly. The evolution of EESC in the Earth's atmosphere is shown in Figure 1h. A drawn-out "fingerprint" of the influence of ODS is visible within the increasing frequency of ELOs in the annual means (Fig. 1c) and in all seasons except autumn (Fig. 2a, b, d) from the 1970s/80s onward.

Enhanced ozone depletion at high northern latitudes, propelled by heterogeneous chemistry on polar stratospheric clouds (PSCs), is regularly observed in late winter and early spring. Ozone depletion is caused by activation of chlorine on PSCs that then catalytically destroys ozone inside the polar vortex (e.g. Peter, 1997; Solomon, 1999). In the chemically undisturbed stratosphere the breakdown of the polar vortex is expected to cause higher ozone values in late winter and spring than under chemically disturbed conditions (ODS). This ODS-induced polar ozone loss has a significant influence on ozone trends observed at mid-latitudes due to mixing of polar air masses after the breakdown of the vortex in northern springtime (Knudsen and Grooss, 2000; Fioletov and Shepherd, 2005).

Contributions of strong polar vortex ozone loss to column ozone over Arosa can be identified from the extremes record. Values of polar ozone loss contributions to total ozone at the northern mid-latitudes (see Fig. 1j) have been taken from Wohltmann et al. (2007). From the mid-1980s onward, during late winter and spring, a strong decline in EHOs is visible for the Arosa record (see Fig. 1c), in particular in spring and winter (see Fig. 2a, d). This decline in EHOs may be related to transport of ozone-rich air from high latitudes; however, since the massive increase in ODS in the early 1980s these ozone-rich events were gradually quenched by high latitude ozone depletion, affecting the Arosa measurements, in particular after the breakdown of the polar vortex. This impact peaks in the spring seasons of 1989-1990, 1993, 1995-1997, 2000 and 2002, when (almost) no EHOs occurred at all in the Arosa record. While the frequency of EHOs dropped during these periods the frequency of ELOs peaked at the same time. Polar ozone loss might have been so large that EHOs in the chemically unperturbed period were replaced by ELOs when winter temperatures were particularly cold. Furthermore transport by southerly winds in the lowermost stratosphere (Koch et al., 2005), also led to an enhancement in ELOs. The latter could be due to dynamic changes such as a broadening of the tropical belt (Hudson et al., 2006), or due to in situ processing in mid-latitudes (Solomon, 1999), or to both.

\section{Influence of extreme events on observed means and trends in total ozone}

This section considers the impact of extreme events on observed mean values and trends in total ozone. This is an interesting question, as we could show that physical and chemical phenomena leave stronger "fingerprints" in the tails of the ozone distribution than in the averaged quantities derived from the dataset (see Fig. 3).

To analyze the influence of extreme events on observed mean values, we excluded (i) the ELOs, (ii) the EHOs, and (iii) both ELOs and EHOs from the Arosa time series. The seasonal averages (Fig. 4a-d) and the annual average (Fig. 4e) of total ozone are shown for the original observed time series (red curves), the ELOs removed from the time series (light blue curves), the EHOs removed from the time series (dark blue curves) and the time series after removing both extremes (black curves). Figure $4 \mathrm{f}$ shows smoothed annual data series before and after removal of extremes to highlight long-term trends. Here the data were smoothed by applying LOESS (LOcally wEighted Scatterplot Smoothing) (e.g. Cleveland, 1979; Cleveland and Devlin, 1988; Cleveland et al., 1990) with a smoothing parameter $q=2 / 3$.

First, we note that the inter-annual variability is strongly reduced when the extremes are removed, indicating that the infrequent extremes strongly influence annual values (as well as seasonal means). During the first decades the observed seasonal averages and the seasonal averages of the ELOsremoved time series follow each other rather closely throughout all seasons (Fig. 4a-d). Conversely, the EHOs-removed averages are in good agreement with the observed averages from the mid-1980s on. Furthermore, the linear downward trend (for 1970-1990) is much weaker throughout all seasons after both extremes are removed, and the annual trend is reduced by a factor of 2.5 , see Fig. $4 \mathrm{f}$ and Table 3 . The strongest trend reduction on the seasonal scale can be observed in spring (about a factor of 3.5), when polar processes add to the general mid-latitude ozone depletion. Table 3 


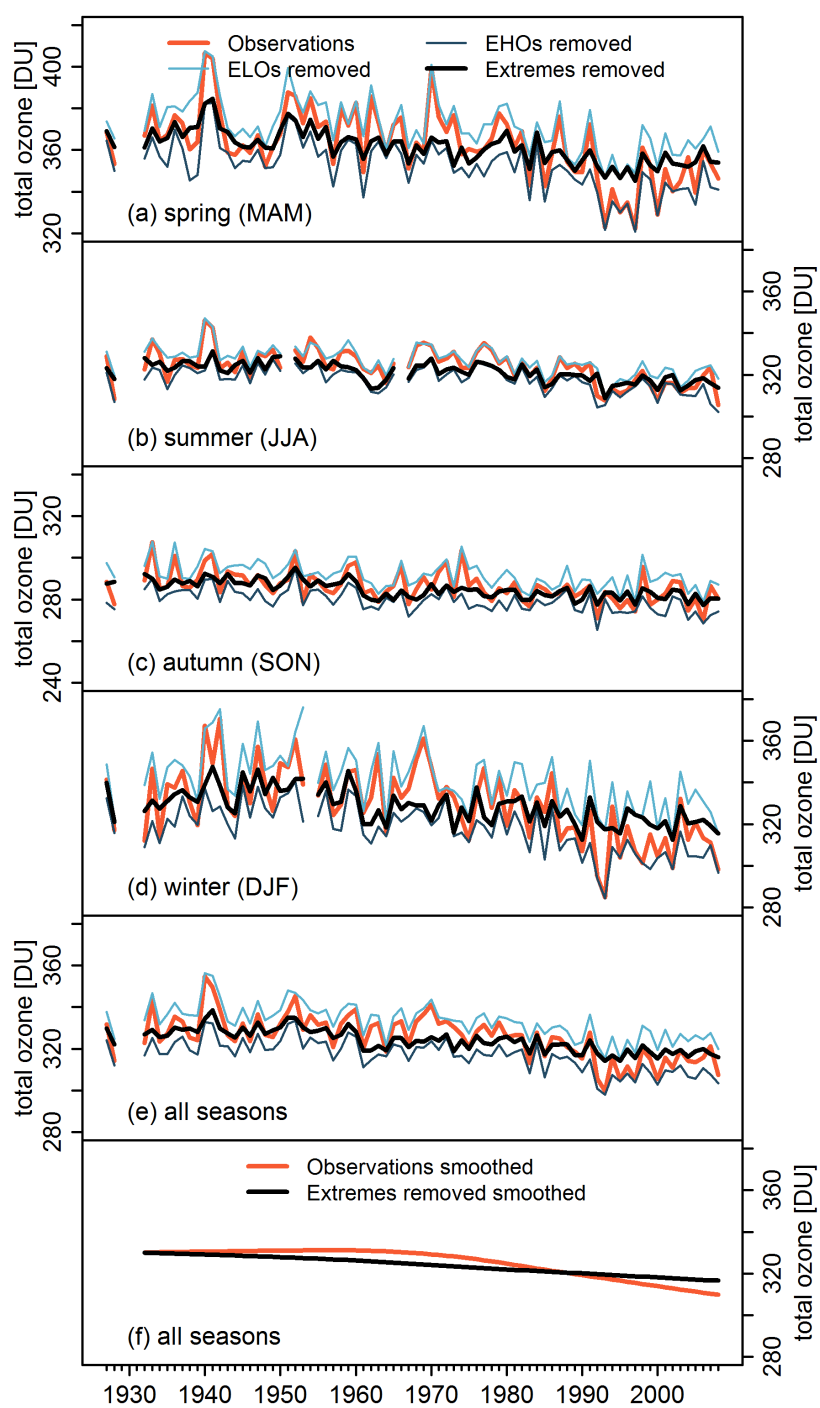

Fig. 4. Total ozone at Arosa, Switzerland, for 1927-2008. Observed (red curves), ELOs-removed (light blue curves), EHOs-removed (dark blue curves) and all extremes removed (black curves) of (ad) seasonal averages, (e) annual averages, and (f) LOESS (LOcally wEighted Scatterplot Smoothing) smoothed (with smoothing parameter $q=2 / 3$ ) observed and extremes removed annual averages.

provides a comparison of linear trends per decade for the original time series and the series after removal of extremes on annual and seasonal basis. From these results it can be concluded that variability and trend in total ozone observations at Arosa are dominated by extreme events in low and high total ozone.

As discussed in Sect. 3.2 the influences of ENSO and NAO (in its negative phase) are captured in the frequency of days with extreme high total ozone, while the influence of NAO (in its positive phase) and influence of volcanic eruption are captured in the frequency of days with extreme low total ozone. The influence of ODS and contributions of strong polar vortex ozone loss after its breakdown through mixing of air masses and transport to northern mid-latitudes are discernible in both tails. However, contributions from polar vortex ozone loss are revealed more clearly in the decreasing frequency of EHOs. Solar cycle and QBO effects are not included in our analysis as they show continuous (not related to the tails) and only small (1-2\%) influence on total ozone.

For annual means, as well as for spring-summer-autumn, we find a stronger trend reduction for the time series without EHOs than for those without ELOs, while in winter the trend reduction is larger when ELOs are removed. Trend reduction is largest in spring, where especially contributions of low ozone from north (after the breakdown of the polar vortex) to Europe can be considered as major influencing variable. In contrast, in winter the time series without ELOs shows a stronger trend reduction, which partly might be related to the mode of the North Atlantic Oscillation, as reported by Appenzeller et al. (2000). Ranking of the influencing factors is difficult in an extreme value analysis context, and determination of the exact contribution of dynamical and chemical factors on ozone changes is difficult as they sometimes occur simultaneously, partly compensating or amplifying each other. As ozone depleting substances are considered to affect both types of extremes (due to enhanced chemical ozone depletion in mid-latitudes and enhanced polar vortex ozone loss) a significant effect of anthropogenical chemical influence on column ozone changes is obvious. However, "fingerprint" analysis shows that dynamical factors influence column ozone too and much more frequently and strongly than previously thought. Several studies estimated an influence of $1 / 3$ (or even higher) of dynamical contributions to ozone changes (e.g. Hood and Soukharev, 2005; WMO, 2007; Wohltmann et al., 2007). From the frequent "fingerprints" found for ENSO and NAO within the presented analysis we conclude that the presented results are in general agreement with these studies. For the individual seasons it seems that the winter trend is more strongly influenced by dynamical changes (through changes in the polar vortex) than those of spring. Importantly, strong ENSO events also contribute significantly to high column ozone during springtime, an effect that might be disguised by the dominating influence of polar vortex contributions during the past two decades.

To quantify the importance of ELOs and EHOs for the Arosa record the influence of ELOs (Eq. 2) and EHOs (Eq. 3) on seasonal and annual averages in total ozone were calculated:

$I_{\mathrm{ELOs}_{(t)}}=M_{\mathrm{ELOs}(\mathrm{ex})_{(t)}}-M_{\mathrm{AROSA}_{(t)}}$

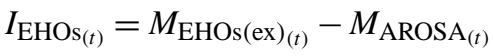

Here $I_{\mathrm{ELOs}}\left(I_{\mathrm{EHOs}}\right)$ is the influence of extreme events in low (high) total ozone on the seasonal or annual mean value, $M_{\text {ELOsex }}\left(M_{\text {EHOs(ex) }}\right)$ is the average total ozone with ELOs (EHOs) excluded from the time series, $M_{\text {AROSA }}$ denotes the 
Table 3. Annual and seasonal linear trends (in \% per decade) for 1970-1990 at Arosa for the observed and extremes removed time series. Standard errors are given in brackets.

\begin{tabular}{lrrrr}
\hline & \multicolumn{3}{c}{ trend (in \% per decade) for 1970-1990 } \\
\cline { 2 - 5 } & Observations & $\begin{array}{r}\text { time series without } \\
\text { EHOs and ELOs }\end{array}$ & $\begin{array}{r}\text { time series } \\
\text { without EHOs }\end{array}$ & $\begin{array}{r}\text { time series } \\
\text { without ELOs }\end{array}$ \\
\hline Annual & $-2.4( \pm 0.5)$ & $-0.9( \pm 0.3)$ & $-1.3( \pm 0.6)$ & $-2( \pm 0.5)$ \\
Spring & $-3.4( \pm 1.0)$ & $-0.9( \pm 0.5)$ & $-1.5( \pm 0.7)$ & $-2.9( \pm 0.8)$ \\
Summer & $-1.5( \pm 0.5)$ & $-0.9( \pm 0.3)$ & $-1.0( \pm 0.5)$ & $-1.2( \pm 0.5)$ \\
Autumn & $-1.6( \pm 0.7)$ & $-0.8( \pm 0.3)$ & $-0.6( \pm 0.4)$ & $-1.5( \pm 0.6)$ \\
Winter & $-2.8( \pm 1.1)$ & $-0.7( \pm 0.7)$ & $-1.8( \pm 0.9)$ & $-1.1( \pm 1.0)$ \\
\hline
\end{tabular}

average total ozone observed over Arosa and $t$ denotes to the averaging time period (seasonal or annual basis).

The influence of ELOs, EHOs and both extremes on annual means of total ozone over Arosa is shown in Fig. 5e, while Fig. 5a-d shows the influence on seasonal averages. In general, patterns identified on seasonal scale, described below, persist also for the influence of ELOs and EHOs on observed annual averages.

The variability in the column ozone, the extremes and the influence of ELOs and EHOs are all generally smaller during fall and summer than during spring and winter. Throughout all seasons, a dominating influence of EHOs is visible until the late 1970s. The influence of ELOs increases from the mid-1970s on, becoming dominant during the 1980s.

EHOs have strongest influence (e.g. $>20$ DU) on observed mean values during wintertime (see Fig. 5d) in 1933, 19401942, 1952, 1962-1963, 1969-1970, 1977 and 1985, and during springtime (see Fig. 5a) in 1940-1941, 1958, 1962, 1970, 1973, 1987 and 1991. In almost all of these years strong influence of ENSO and/or NAO (negative phase) can be identified. The average influence of EHOs on observed mean values is $10 \mathrm{DU}$ in spring, $6 \mathrm{DU}$ in summer and autumn and $12 \mathrm{DU}$ in winter.

ELOs have strongest influence (e.g. $>-20 \mathrm{DU}$ ) on observed mean values in winter (see Fig. 5d) in 1932, 1949, 1953-1954, 1992-1993 and 1999 and spring (see Fig. 5a) in 1938-1939, 1985, 1993, 1997, 2000 and 2005. In almost all of these years strong influence of NAO (positive phase) and/or contributions of polar vortex ozone loss can be identified. Furthermore, the eruption of Mt. Pinatubo (June 1991) led to an increase in the total number of ELOs and their contribution to mean values in the years after the eruption. The average influence of ELOs on observed mean values of column ozone is about $-9 \mathrm{DU}$ in spring, $-3 \mathrm{DU}$ in summer, $-5 \mathrm{DU}$ in autumn and $-12 \mathrm{DU}$ in winter.

\section{Conclusions}

We found in all seasons that a large fraction of the variability and trend in the total ozone time series at Arosa (Switzerland) can be attributed to extreme events (ELOs and EHOs). Clear "fingerprints" of atmospheric dynamics (ENSO, NAO), the major volcanic eruptions of the 20th century (Gunug Agung, El Chichón and Mt. Pinatubo) and atmospheric chemistry (contributions of ODS and in particular polar vortex ozone loss) are discernible in the frequency distributions of extreme events. Fingerprint analysis of the tails in the ozone distribution function, i.e. of the extreme events, allows attribution of the influence of the chemical and dynamical factors in a more systematic manner than a mean value analysis can achieve. Fingerprint analysis reveals that these chemical and dynamical factors affect total ozone much more frequently and strongly than thought previously. In comparison to previous studies (e.g. Appenzeller et al., 2000; Orsolini and Limpasuvan, 2001; Orsolini and Doblas-Reyes, 2003; Brönnimann et al., 2004b; Sassi et al., 2004) we showed that moderate ENSO and NAO events also have a significant influence on total ozone. During years with strong polar vortex ozone loss we could further show that the frequency distribution of total ozone changes significantly; especially interesting is the almost complete erosion in extreme high values during the past three decades. Strong influence of volcanic eruptions has previously been documented in the scientific literature; however, from our results we note to see that their impact influences both tails (strong increase in ELOs and erosion in EHOs), suggesting that the depletion is ubiquitous. It is further important to note that various chemical and dynamical factors sometimes occur simultaneously, partly compensating or amplifying each other (e.g. ENSO, NAO, and polar vortex ozone depletion), so that the individual contributions to a specific fingerprint are hard to distinguish. Further it was shown that the influence of EHOs and ELOs on seasonal and annual averages changed strongly with time. While EHOs show a strong influence on seasonal and annual means during the first half of the 20th century, the influence of ELOs on the means became larger starting in the mid-1980s. The 


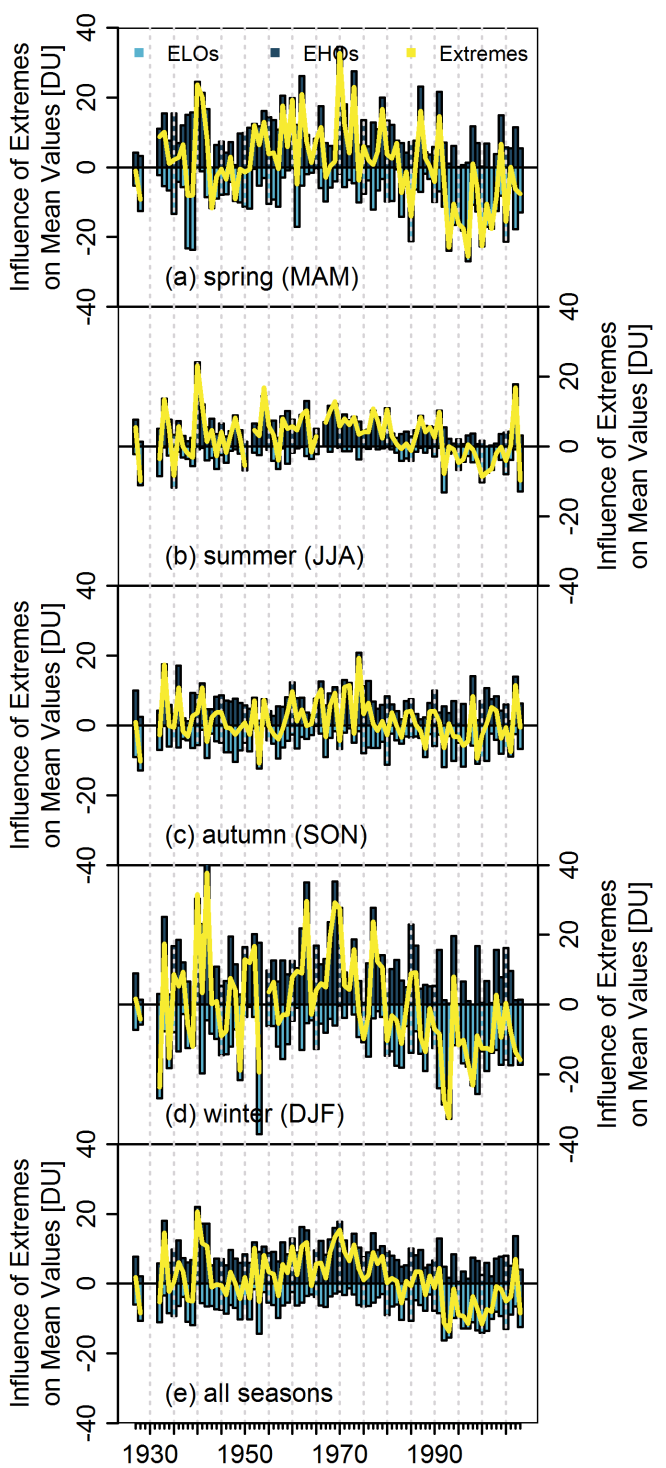

Fig. 5. Influence (according to Eqs. 1 and 2) of ELOs (light blue histogram) and EHOs (dark blue histogram) and of both extremes (yellow curve) in DU/year on (a-d) seasonal means and (e) annual mean of total ozone over Arosa, Switzerland, 1927-2008.

comparison of the means of the original observation record with those from the time series with (i) ELOs, (ii) EHOs, and (iii) both extremes removed confirmed these findings and showed further that trends are strongly reduced (on average by a factor of 2.5) when both extremes are removed.

The application of extreme value theory provides deeper insight into time series properties and a more complete attribution of the influence of dynamical and chemical factors on total ozone variability than the analysis using standard metrics would allow.
Acknowledgements. This work was performed within the project EXTREMES: "Spatial extremes and environmental sustainability: Statistical methods and applications in geophysics and the environment", funded by the Competence Centre for the Environment and Sustainability (CCES) within the ETH-domain in Switzerland.

The authors are grateful to Ingo Wohltmann for providing data on polar vortex contributions to ozone loss in the northern midlatitudes.

The Software R (R Development Core Team, http://www.R-project. org) was used for the statistical analysis.

The authors are grateful to Robert Lund and one anonymous referee for useful comments during the discussion phase in ACPD. Further the authors are grateful to another anonymous referee for comments during the revision phase of the article.

Edited by: M. Dameris

\section{References}

Alexander, M. J., Tsuda, T., and Vincent, R. A.: Latitudinal variations observed in gravity waves with short vertical wavelengths, J. Atmos. Sci., 59, 1394-1404, 2002.

Appenzeller, C., Weiss, A. K., and Staehelin, J.: North Atlantic oscillation modulates total ozone winter trends, Geophys. Res. Lett., 27, 1131-1134, 2000.

Austin, J. and Wilson, R. J.: Ensemble simulations of the decline and recovery of stratospheric ozone, J. Geophys. Res.-Atmos., 111, D16314, doi:10.1029/2005jd006907, 2006.

Braesicke, P. and Pyle, J. A.: Changing ozone and changing circulation in northern mid-latitudes: Possible feedbacks?, Geophys. Res. Lett., 30, 1059, doi:10.1029/2002g1015973, 2003.

Brasseur, G. and Granier, C.: Mount Pinatubo aerosols, chlorofluorocarbons and ozone depletion, Science, 257, 1239-1242, 1992.

Brönnimann, S. and Hood, L. L.: Frequency of low-ozone events over northwestern Europe in 1952-1963 and 1990-2000, Geophys. Res. Lett., 30, ASC8-1-5, doi:10.1029/2003gl018431, 2003.

Brönnimann, S., Luterbacher, J., Staehelin, J., and Svendby, T. M.: An extreme anomaly in stratospheric ozone over Europe in 1940-1942, Geophys. Res. Lett., 31, L08101, doi:10.1029/2004gl019611, 2004a.

Brönnimann, S., Luterbacher, J., Staehelin, J., Svendby, T. M., Hansen, G., and Svenoe, T.: Extreme climate of the global troposphere and stratosphere in 1940-42 related to El Nino, Nature, 431, 971-974, doi:10.1038/nature02982, 2004b.

Calbo, J., Pages, D., and Gonzalez, J. A.: Empirical studies of cloud effects on UV radiation: A review, Rev. Geophys., 43, RG2002, doi:10.1029/2004rg000155, 2005.

Chandra, S., Varotsos, C., and Flynn, L. E.: The mid-latitude total ozone trends in the northern hemisphere, Geophys. Res. Lett., 23, 555-558, 1996.

Chipperfield, M. P. and Jones, R. L.: Relative influences of atmospheric chemistry and transport on Arctic ozone trends, Nature, 400, 551-554, 1999.

Cicerone, R. J., Stolarski, R. S., and Walters, S.: Stratospheric ozone destruction by man-made chlorofluoromethanes, Science, $185,1165-1167,1974$ 
Cleveland, R. B., Cleveland, W. S., McRae J. A., and Terpenning, I.: STL: A Seasonal-Trend Decomposition Procedure Based on Loess, Journal of Official Statistics, 6(1), 3-73, 1990.

Cleveland, W. S.: Robust locally weighted regression and smoothing scatterplots, J. Amer. Statistical Assoc., 74, 829-836, 1979.

Cleveland, W. S. and Devlin, S. J.: Locally weighted regression - an approach to regression analysis by local fitting, J. Amer. Statistical Assoc., 83, 596-610, 1988.

Coles, S.: An introduction to statistical modeling of extreme values Springer series in Statistics, Springer, London, 2001.

Davison, A. C. and Smith, R. L.: Models for exceedances over high thresholds (with Discussion), Journal of the Royal Statistical Society Series B, 52, 393-442, 1990.

Dobson, G. M. B. and Harrison, D. N.: Measurements of the amount of ozone in the earth's atmosphere and its relation to other geophysical conditions, Proceedings of the Royal Society of London Series a-Containing Papers of a Mathematical and Physical Character, 110, 660-693, 1926.

Eyring, V., Waugh, D. W., Bodeker, G. E., Cordero, E., Akiyoshi, H., Austin, J., Beagley, S. R., Boville, B. A., Braesicke, P., Bruhl, C., Butchart, N., Chipperfield, M. P., Dameris, M., Deckert, R., Deushi, M., Frith, S. M., Garcia, R. R., Gettelman, A., Giorgetta, M. A., Kinnison, D. E., Mancini, E., Manzini, E., Marsh, D. R., Marches, S., Nagashima, T., Newman, P. A., Nielsen, J. E., Pawson, S., Pitari, G., Plummer, D. A., Rozanov, E., Schraner, M., Scinocca, J. F., Semeniuk, K., Shepherd, T. G., Shibata, K., Steil, B., Stolarski, R. S., Tian, W., and Yoshiki, M.: Multimodel projections of stratospheric ozone in the 21st century, J. Geophys. Res., 112, D16303, doi:10.1029/2006JD008332, 2007.

Fioletov, V. E. and Shepherd, T. G.: Summertime total ozone variations over middle and polar latitudes, Geophys. Res. Lett., 32, L04807, doi:10.1029/2004g1022080, 2005.

Friedrich, K. and Müller, K.: Climate anomalies in Europe associated with ENSO extremes, Int. J. Climatol., 12, 25-31, 1992.

Greatbatch, R. J., Lu, J., and Peterson, K. A.: Nonstationary impact of ENSO on Euro-Atlantic winter climate, Geophys. Res. Lett., 31, L02208, doi:10.1029/2003GL018542, 2004.

Grams, G. and Fiocco, G.: Stratospheric aerosol layer during 1964 and 1965, J. Geophys. Res., 72, 3523-3542, 1967.

Hadjinicolaou, P., Pyle, J. A., Chipperfield, M. P., and Kettleborough, J. A.: Effect of interannual meteorological variability on mid-latitude O-3, Geophys. Res. Lett., 24, 2993-2996, 1997.

Hadjinicolaou, P., Jrrar, A., Pyle, J. A., and Bishop, L.: The dynamically driven long-term trend in stratospheric ozone over northern middle latitudes, Q. J. Roy. Meteorol. Soc., 128, 1393-1412, 2002.

Harris, N. R. P., Kyrö, E., Staehelin, J., Brunner, D., Andersen, S.B., Godin-Beekmann, S., Dhomse, S., Hadjinicolaou, P., Hansen, G., Isaksen, I., Jrrar, A., Karpetchko, A., Kivi, R., Knudsen, B., Krizan, P., Lastovicka, J., Maeder, J., Orsolini, Y., Pyle, J. A., Rex, M., Vanicek, K., Weber, M., Wohltmann, I., Zanis, P., and Zerefos, C.: Ozone trends at northern mid- and high latitudes a European perspective, Ann. Geophys., 26, 1207-1220, doi:10.5194/angeo-26-1207-2008, 2008.

Hartmann, D. L., Wallace, J. M., Limpasuvan, V., Thompson, D. W. J., and Holton, J. R.: Can ozone depletion and global warming interact to produce rapid climate change?, P. Natl. Acad. Sci. USA, 97, 1412-1417, 2000.

Hastie, T. J. and Pregibon, D.: Generalized linear models, in: Sta- tistical Models in S, edited by: Chambers, J. M. and Hastie, T. J., Wadsworth and Brooks/Cole, 1992.

Hegglin, M. I. and Shepherd, T. G.: Large climate-induced changes in ultraviolet index and stratosphere-to-troposphere ozone flux, Nat. Geosci., 2, 687-691, doi:10.1038/ngeo604, 2009.

Hood, L. L. and Zaff, D. A.: Lower stratospheric stationary waves and the longitude dependence of ozone trends in winter, J. Geophys. Res.-Atmos., 100, 25791-25800, 1995.

Hood, L. L.: The solar cycle variation of total ozone: Dynamical forcing in the lower stratosphere, J. Geophys. Res.-Atmos., 102, 1355-1370, 1997.

Hood, L. L. and Soukharev, B. E.: Interannual variations of total ozone at northern midlatitudes correlated with stratospheric EP flux and potential vorticity, J. Atmos. Sci., 62, 3724-3740, 2005.

Hudson, R. D., Andrade, M. F., Follette, M. B., and Frolov, A. D.: The total ozone field separated into meteorological regimes Part II: Northern Hemisphere mid-latitude total ozone trends, Atmos. Chem. Phys., 6, 5183-5191, doi:10.5194/acp-6-5183-2006, 2006.

Hurrell, J. W.: Decadal trends in the North-Atlantic Oscillation Regional temperatures and precipitation, Science, 269, 676-679, 1995.

Hurrell, J. W.: The principal component (PC) time series of the leading EOF of seasonal SLP anomalies over the Atlantic sector (20-80 N, $90 \mathrm{~W}-40 \mathrm{E})$, available since 1899, data set available online at: http://www.cgd.ucar.edu/cas/jhurrell/indices. html, 2009.

Jaeger, H. and Wege, K.: Stratospheric ozone depletion at northern midlatitudes after major volcanic-eruptions, J. Atmos. Chem., 10, 273-287, 1990.

Knudsen, B. M. and Grooss, J. U.: Northern midlatitude stratospheric ozone dilution in spring modeled with simulated mixing, J. Geophys. Res.-Atmos., 105, 6885-6890, 2000.

Koch, G., Wernli, H., Schwierz, C., Staehelin, J., and Peter, T.: A composite study on the structure and formation of ozone miniholes and minihighs over central Europe, Geophys. Res. Lett., 32, L12810, doi:10.1029/2004g1022062, 2005.

Kodera, K.: Influence of volcanic eruptions on the troposphere through stratospheric dyanamical processes in the northernhemisphere winter, J. Geophys. Res.-Atmos., 99, 1273-1282, 1994.

Labitzke, K. G. and van Loon, H.: The Stratosphere, Phenomena, History, and Relevance, Springer, Berlin, 1999.

Lau, N. C.: Variability of the observed midlatitude storm tracks in relation to low-frequency changes in the circulation pattern, $\mathrm{J}$. Atmos. Sci., 45, 2718-2743, 1988.

Mäder, J. A., Staehelin, J., Brunner, D., Stahel, W. A., Wohltmann, I., and Peter, T.: Statistical modeling of total ozone: Selection of appropriate explanatory variables, J. Geophys. Res.-Atmos., 112, D11108, doi:10.1029/2006jd007694, 2007.

McCormick, M. P., Thomason, L. W., and Trepte, C. R.: Atmospheric effects of the mt-pinatubo eruption, Nature, 373, 399404, 1995.

McCullagh, P. and Nelder, J. A.: Generalized Linear Models, Chapman and Hall, London, 1989.

Merkel, U. and Latif, M.: A high resolution AGCM study of the El Nino impact on the North Atlantic/European sector, Geophys. Res. Lett., 29, 1291, doi:10.1029/2001GL013726, 2002.

Molina, M. J. and Rowland, F. S.: Stratospheric sink for chloroflu- 
oromethanes - chlorine atomic-catalysed destruction of ozone, Nature, 249, 810-812, 1974.

Newman, P. A. and Nash, E. R.: Quantifying the wave driving of the stratosphere, J. Geophys. Res.-Atmos., 105, 12485-12497, 2000.

Newman, P. A., Nash, E. R., and Rosenfield, J.: What controls the temperature of the arctic stratosphere during the spring?, J. Geophys. Res., 106, 19999-20010, 2001.

Orsolini, Y. J. and Limpasuvan, V.: The North Atlantic Oscillation and the occurrences of ozone miniholes, Geophys. Res. Lett., 28, 4099-4102, 2001.

Orsolini, Y. J. and Doblas-Reyes, F. J.: Ozone signatures of climate patterns over the Euro-Atlantic sector in the spring, Q. J. Roy. Meteorol. Soc., 129, 3251-3263, doi:10.1256/qj.02.165, 2003.

Pawson, S. and Naujokat, B.: The cold winters of the middle 1990s in the northern lower stratosphere, J. Geophys. Res.-Atmos., 104, 14209-14222, 1999.

Peter, T.: Microphysics and heterogeneous chemistry of polar stratospheric clouds, Ann. Rev. Phys. Chem., 48, 785-822, 1997.

Pickands, J.: Statistical-inference using extreme order statistics, Ann. Stat., 3, 119-131, 1975.

Pittock, A. B.: Possible destruction of ozone by volcanic material at 50 MBAR, Nature, 207, p. 182, 1965.

Pozo-Vazquez, D., Esteban-Parra, M. J., Rodrigo, F. S., and CastroDiez, Y.: The association between ENSO and winter atmospheric circulation and temperature in the North Atlantic region, J. Clim., 14, 3408-3420, 2001.

Randel, W. J. and Wu, F.: Cooling of the arctic and antarctic polar stratospheres due to ozone depletion, J. Clim., 12, 1467-1479, 1999.

Randel, W. J., Wu, F., and Stolarski, R.: Changes in column ozone correlated with the stratospheric EP flux, J. Meteorol. Soc. Japan, 80, 849-862, 2002.

Rieder, H. E., Staehelin, J., Maeder, J. A., Peter, T., Ribatet, M., Davison, A. C., Stübi, R., Weihs, P., and Holawe, F.: Extreme events in total ozone over Arosa - Part 1: Application of extreme value theory, Atmos. Chem. Phys., 10, 10021-10031, doi:10.5194/acp-10-10021-2010, 2010.

Robock, A.: Volcanic eruptions and climate, Rev. Geophys., 38, 191-219, 2000.

Rowland, F. S. and Molina, M. J.: Chlorofluoromethanes in environment, Rev. Geophys., 13, 1-35, 1975.

Sassi, F., Kinnison, D., Boville, B. A., Garcia, R. R., and Roble, R.: Effect of El Nino-Southern Oscillation on the dynamical, thermal, and chemical structure of the middle atmosphere, J. Geophys. Res.-Atmos., 109, D17108, doi:10.1029/2003jd004434, 2004.

Sato, M., Hansen, J. E., McCormick, M. P., and Pollack, J. B.: Stratospheric aerosol optical depths, 1850-1990, J. Geophys. Res.-Atmos., 98, 22987-22994, 1993.

Seidel, D. J., Fu, Q., Randel, W. J., and Reichler, T. J.: Widening of the tropical belt in a changing climate, Nat. Geosci., 1, 21-24, doi:10.1038/ngeo.2007.38, 2008.

Shepherd, T. G.: Dynamics, stratospheric ozone, and climate change, Atmos.-Ocean, 46, 117-138, doi:10.3137/ao.460106, 2008 .
Solomon, S.: Stratospheric ozone depletion: A review of concepts and history, Rev. Geophys., 37, 275-316, 1999.

Staehelin, J., Kegel, R., and Harris, N. R. P.: Trend analysis of the homogenized total ozone series of Arosa (Switzerland), 19261996, J. Geophys. Res.-Atmos., 103, 8389-8399, 1998a.

Staehelin, J., Renaud, A., Bader, J., McPeters, R., Viatte, P., Hoegger, B., Bugnion, V., Giroud, M., and Schill, H.: Total ozone series at Arosa (Switzerland): Homogenization and data comparison, J. Geophys. Res.-Atmos., 103, 5827-5841, 1998b.

Staehelin, J., Harris, N. R. P., Appenzeller, C., and Eberhard, J.: Ozone trends: A review, Rev. Geophys., 39, 231-290, 2001.

Steinbrecht, W., Claude, H., Kohler, U., and Hoinka, K. P.: Correlations between tropopause height and total ozone: Implications for long-term changes, J. Geophys. Res.-Atmos., 103, 1918319192, 1998.

Thompson, D. W. J. and Wallace, J. M.: The Arctic Oscillation signature in the wintertime geopotential height and temperature fields, Geophys. Res. Lett., 25, 1297-1300, 1998.

Thompson, D. W. J. and Wallace, J. M.: Annular modes in the extratropical circulation. Part I: Month-to-month variability, J. Clim., 13, 1000-1016, 2000.

Trenberth, K. E., Branstator, G. W., Karoly, D., Kumar, A., Lau, N. C., and Ropelewski, C.: Progress during TOGA in understanding and modeling global teleconnections associated with tropical sea surface temperatures, J. Geophys. Res.-Oceans, 103, 1429114324, 1998.

van Loon, H. and Labitzke, K.: The Southern Oscillation. Part V: The anomalies in the lower stratosphere of the Northern Hemisphere in winter and a comparison with the Quasi-Biennial Oscillation, Mon. Weather Rev., 115, 357-369, 1987.

Volodin, E. M. and Galin, V. Y.: Sensitivity of midlatitude northern hemisphere winter circulation to ozone depletion in the lower stratosphere, Russ. Meteorol. Hydrol., 8, 23-32, 1998.

Vyushin, D. I., Fioletov, V. E., and Shepherd, T. G.: Impact of longrange correlations on trend detection in total ozone, J. Geophys. Res.-Atmos., 112, D14307, doi:10.1029/2006jd008168, 2007.

Wallace, J. M.: North Atlantic Oscillation/annular mode: Two paradigms - one phenomenon, Q. J. Roy. Meteorol. Soc., 126, 791-805, 2000.

Waugh, D. W., Oman, L., Kawa, S. R., Stolarski, R. S., Pawson, S., Douglass, A. R., Newman, P. A., and Nielsen, J. E.: Impacts of climate change on stratospheric ozone recovery, Geophys. Res. Lett., 36, L03805, doi:10.1029/2008gl036223, 2009.

WMO: Scientific Assessment of Ozone Depletion: 2002, Global Ozone Reserach and Montitoring Project 47, 498, 2003.

WMO: Scientific Assessment of Ozone Depletion: 2006, Global Ozone Reserach and Montitoring Project 50, 572, 2007.

Wohltmann, I., Lehmann, R., Rex, M., Brunner, D., and Mader, J. A.: A process-oriented regression model for column ozone, J. Geophys. Res.-Atmos., 112, D12304, doi:10.1029/2006jd007573, 2007.

Yue, G. K., McCormick, M. P., and Chiou, E. W.: Stratospheric aerosol optical depth observed by the stratospheric aerosol and gas experiment .2. decay of the el-chichon and ruiz volcanic perturbations, J. Geophys. Res.-Atmos., 96, 5209-5219, 1991. 